\title{
Comparison of estimated energy intake from $2 \times 24$-hour recalls and a seven-day food record with objective measurements of energy expenditure in children
}

\author{
Berit W. Rothausen '*, Jeppe Matthiessen', Margit V. Groth', \\ Per B. Brockhoff ${ }^{2}$, Lene F. Andersen ${ }^{3}$ and Ellen Trolle
}

'Division of Nutrition, National Food Institute, Technical University of Denmark, Søborg, Denmark; ${ }^{2}$ Department of Informatics and Mathematical Modeling, Technical University of Denmark, Kongens Lyngby, Denmark; ${ }^{3}$ Department of Nutrition, Institute of Basic Medical Sciences, University of Oslo, Oslo, Norway

Abstract

Objective: The objective of the present study was to evaluate energy intake (EI) estimated from two nonconsecutive 24-hour recalls (24-HDRs) and a pre-coded seven-day food record (7-dFR) against objective measurements of energy expenditure (EE) in children.

Design: A total of 67 7-8 year-olds and 64 12-13 year-olds completed the $2 \times 24-H D R s$, the $7-\mathrm{dFR}$, and wore ActiReg $^{\circledR}$ (PreMed AS, Oslo, Norway), a combined position and motion recording instrument, during the same seven days as the 7-dFR was filled in.

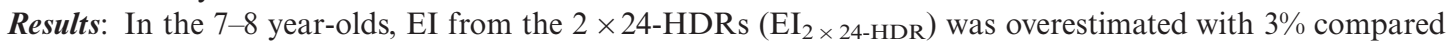
to EE (not significantly different), while EI from the $7-\mathrm{dFR}_{(}\left(\mathrm{EI}_{7-\mathrm{dFR}}\right)$ was underestimated with $7 \%$ compared to $\mathrm{EE}(P=0.001)$. In the $12-13$ year-olds, the corresponding figures was underestimation by $10 \%$ with the $2 \times 24$-HDRs $(P<0.001)$ and by $20 \%$ with the 7 -dFR $(P<0.001)$. For both age groups combined, the $95 \%$ limits of agreement were -4.38 and $3.52 \mathrm{MJ} / \mathrm{d}$ for the $2 \times 24-\mathrm{HDRs}$, and -5.90 and $2.94 \mathrm{MJ} / \mathrm{d}$ for the 7-dFR. Pearson correlation coefficients between EI and EE were 0.51 for $\mathrm{EI}_{2 \times 24-\mathrm{HDR}}$ and 0.29 for $\mathrm{EI}_{7-\mathrm{dFR}}$, respectively. The proportion classified in the same or adjacent quartiles was $76 \%$ for $\mathrm{EI}_{2 \times 24-\mathrm{HDR}}$ and $73 \%$ for $\mathrm{EI}_{7-\mathrm{dFR}}$ in the $7-8$ year-olds, and $83 \%$ for $\mathrm{EI}_{2 \times 24-\mathrm{HDR}}$ and $70 \%$ for $\mathrm{EI}_{7-\mathrm{dFR}}$ in the $12-13$ year-olds.

Conclusion: Misreporting of EI seemed modest with both the $2 \times 24$-HDRs and the 7 -dFR in the 7-8 year-olds when compared to EE measured with ActiReg ${ }^{\circledR}$. Under-reporting appeared to be more evident in the 12-13 year-olds, especially with the $7-\mathrm{dFR}$. Compared to measurements of EE, the $2 \times 24-\mathrm{HDR}$ seemed to perform slightly better than the 7-dFR in terms of ranking of individuals according to EI.

Keywords: dietary assessment; EFCOVAL; ActiReg ${ }^{\circledR}$

Received: I4 November 20II; Revised: 10 January 20I2; Accepted: 12 January 20 I2; Published: 15 February 2012

$\mathrm{I}$ n nutritional epidemiology it is essential to have dietary assessment methods that are valid and feasible for use in large studies. Still, there is no dietary assessment method that is widely accepted as the best choice for such surveys in children, and further development of cost-effective methods is needed (1).

Misreporting of dietary intake is a common problem with dietary assessment methods in both children and adults $(2,3)$. This bias is of concern for the evaluation of food and nutrient intakes as well as for the assessment of associations between dietary intake and health.
Evaluation of new dietary assessment tools is therefore required to reveal the extent of potential misreporting. This is often performed by relative validation comparing the new tool against another dietary assessment method, and/or by comparing energy intake (EI) with objective measurements of energy expenditure (EE). Doubly labelled water (DLW) is considered to be the gold standard reference method for validation of measurements of EI (4). However, the cost and requirements of highly specialised equipment with the DLW method precludes its use in many studies, and more feasible and 
cost-effective ways of measuring EE, such as the use of physical activity monitors, must be applied instead.

One of the main objectives of the EFCOVAL (European Food Consumption Validation) study was to develop and evaluate a trans-European methodology to be used for estimating the intake of foods, nutrients and potentially hazardous chemicals in representative dietary surveys in children (5). According to the EFCOVAL study, the method suggested for children, 7-14 years of age, was the use of two non-consecutive 24-hour recalls (24-HDRs), using the EPIC-Soft computer program, combined with a food recording booklet $(6,7)$. A relative validation of the suggested $2 \times 24$-HDR method was performed against the seven-day pre-coded food record (7-dFR) used in the Danish National Survey of Dietary Habits and Physical Activity 2003-2008. Results from this study are presented elsewhere (8).

The objective of the present study was to compare estimated EI from the $2 \times 24-\mathrm{HDR}$ and the $7-\mathrm{dFR}$, by comparison with EE measured by use of ActiReg ${ }^{\circledR}$ (PreMed AS, Oslo, Norway), a combined position and motion recording instrument, in Danish children aged 7-8 years and $12-13$ years.

\section{Methods}

\section{Participants}

Participants in the age of 7-8 years and 12-13 years were recruited through the Central Office of Civil Registration, using a random sample, stratified by age, from the Capital region of Denmark. An invitation letter was sent to a total of 1,900 children and their parents, of which 170 responded. Of these, 22 responded too late and nine dropped out. Additionally six children were recruited through worksites to ensure the target sample size. Children and parents, who volunteered to participate, were contacted by telephone and received further written information about the study. Written informed consent was obtained from a parent of each child prior to their participation.

\section{Study design}

The data collection took place between August 2008 and April 2009. Participation included completion of two non-consecutive 24-HDRs, a pre-coded 7-dFR and objective assessment of EE by use of ActiReg ${ }^{\circledR}$ during the same seven days as the $7-\mathrm{dFR}$ was filled in. A flow chart of the measurements of dietary intake and energy expenditure is presented in Fig. 1. Trained interviewers visited the participants at their homes and conducted the 24-HDRs on two scheduled visits. The recalls were aimed to be separated by around 4 to 6 weeks. The mean number of days between the two 24-HDRs was 36 days (range 21-83) for the 7-8 year-olds and 39 days (range 28-76) for the 12-13 year-olds. All days of the week were randomly assigned for both recalls in order to obtain an equal representation of weekdays at group level. Anthropometric measurements were made after the recall at the first visit. After the recall at the second visit, participants were provided with detailed instructions on how to fill in the 7-dFR and how to use ActiReg ${ }^{\circledR}$ during the seven-day recording period. The recordings were started on the following day. Participants were instructed to report all food items consumed on the days with dietary intake assessment and to maintain their usual eating and activity patterns. For each participant, a minimum of four valid days with concurrent measurements from the 7-dFR and ActiReg ${ }^{\circledR}$ was required for inclusion in the analyses. The study was approved by the Ethical Committee of the Municipalities of Copenhagen and Frederiksberg and by the Danish Data Protection Agency.

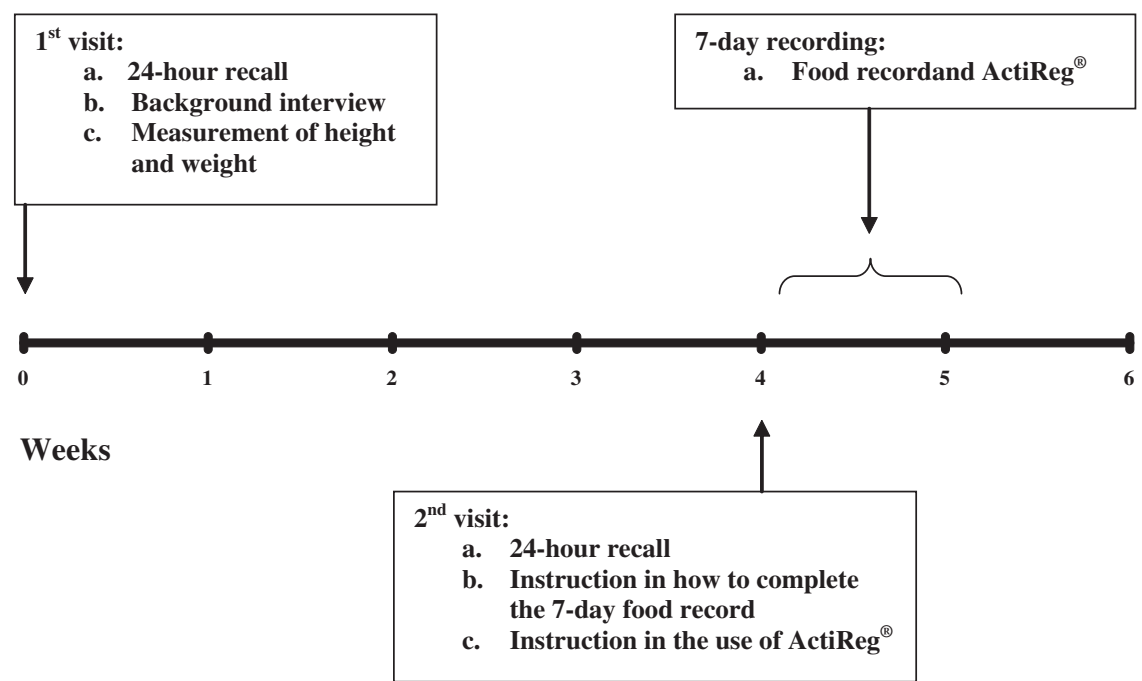

Fig. 1. Flow chart of the measurements of dietary intake, energy expenditure and anthropometry 


\section{4-hour recalls}

The 24-HDR method were based on face-to-face computer-assisted interviews using the standardised recall interview program EPIC-Soft (7), and comprised of four main steps:

(1) General information (non-dietary);

(2) Quick list (chronological list of consumed foods without quantification);

(3) Description and quantification of foods and recipes;

(4) Quality controls at the nutrient level.

One of the parents was present during the interviews and assisted with supplementary information when necessary (description of food intake, information about recipes, cooking methods etc.). The EPIC-Soft version employed was a country-specific version, updated prior to the study in order to cover new food items and to meet the specific requirements of this study. Participants received a food recording booklet for the children to take to school or to other places outside of the home on the days of assessment, i.e. the day before each 24-HDR. If relevant, proxy persons (school staff, day care staff, or others) were contacted in advance and asked to help the children with the booklet. The quantities of foods consumed were estimated from predefined household measures (cups, spoons, slices, etc.) or photos from the EPIC-Soft picture book. In addition, some country specific picture series on candy, rye- and wheat bread, and fat and filling on bread was used. The mean EI/day from the $2 \times 24$-HDRs $\left(\mathrm{EI}_{2} \times 24-\mathrm{HDR}\right)$ was calculated for each individual using the EPIC-Soft software and the Danish Food Composition Databank (version 7; Søborg; Denmark; December 2008, www.foodcomp.dk).

\section{Pre-coded food record}

Dietary intake was recorded every day for seven consecutive days in food records with pre-coded response categories, which included open answer options. The parents were responsible for completing the 7-dFR and deciding to what extent their children were capable of assisting. The 7-dFR, which was identical to the dietary assessment method used in the Danish National Survey of Dietary Habits and Physical Activity 2003-2008, was organised according to the typical Danish meal pattern (breakfast, lunch, dinner and in-between meals). Each meal was divided into sections with headings such as beverages, bread, spreadable fats, meat and vegetables to make it easier to find and record the relevant foods, dishes and beverages (9). For food items not included in the 7-dFR, the participants wrote type of food and portion size in open-answer categories. The quantities of foods consumed were given in predefined household measures (cups, spoons, slices, etc.) or estimated from photos of various portion sizes. Participants also received a food recording booklet for the children to take to school or to other places outside of the home on the days of assessment. Data were scanned using The Eyes \& Hands program (version 5.2, 2005; Readsoft Ltd, Milton Keynes, Buckinghamshire, UK). The mean EI/day from the 7-dFR ( $\left.\mathrm{EI}_{7-\mathrm{dFR}}\right)$ was calculated for each individual using the software system General Intake Estimation System (GIES) (version 0.995a, released 26 June 2005), developed at the National Food Institute, Technical University of Denmark (Søborg, Denmark), and the Danish Food Composition Databank (version 7; Søborg; Denmark; December 2008, http://www.foodcomp.dk).

\section{ActiReg $^{\circledR}$}

The ActiReg ${ }^{\circledR}$ system (PreMed AS, Norway) consists of a multisensor activity monitor (ActiReg ${ }^{\circledR}$ ) and a computer program (ActiCalc $32^{\circledR}$ ) for processing the ActiReg $^{\circledR}$ data. The monitor has two pairs of sensors one body position sensor and one motion sensor in each pair - connected by thin cables to a battery-operated storage unit $(82 \times 45 \times 15 \mathrm{~mm})$ that was placed in an elastic belt around the waist. Each pair of sensors was attached by medical tape, one over the sternum and one at the front of the right thigh approximately midway between the hip and the knee. Stored data were transferred to a computer and processed by the ActiCalc $32^{\circledR}$ program. More details about the use of the ActiReg ${ }^{\circledR}$ system and validation of the method are published elsewhere (10).

In the present study mean EE/day was calculated for each individual by the ActiCalc ${ }^{\circledR}$ program using estimated basal metabolic rate (BMR). Estimates of BMR were calculated from equations, based on age, gender, height and weight (11). Participants were instructed to carry ActiReg ${ }^{\circledR}$ for seven consecutive days during all waking hours except during activities in water, such as swimming, showering, etc., and if needed, during high contact sports. During the night when the children were sleeping, the ActiReg ${ }^{\circledR}$ equipment was taken off and placed in a horizontal position as this mimics the recording of lying still. If the monitor was taken off for a period of 15 minutes or more during daytime, the participants were instructed to record the duration and type of activity performed. A major part of the non-wear time was due to sports activities and subsequent showering and changing clothes. EE during nonwear time was therefore estimated as corresponding to an average activity level of moderate intensity $\left(\mathrm{MET}^{1}=3\right)$. To ensure that the majority of the waking hours was recorded, limits on total wear time and non-wear time were applied. Thus, if ActiReg ${ }^{\circledR}$ was not carried for three hours or more during daytime, and/or total wear time was less than 10 hours per day, the day was omitted from analysis $(12,13)$. 


\section{Anthropometric measurements}

Height and body weight were measured twice in all participants and the mean values were used. Participants were weighed without shoes in light indoor clothing to the nearest $0.1 \mathrm{~kg}$ on a digital personal scale (Soehnle Verona 63686, Quattrotronic scale). Height was measured without shoes to the nearest $\mathrm{cm}$ with an ultrasonic height measuring device (Soehnle S20).

\section{Definition of acceptable reporters and misreporters}

The accuracy of the recorded EI was assessed using the confidence limits of agreement between recorded EI and EE at the individual level (14). Participants were classified as acceptable reporters, under-reporters, or overreporters according to whether the individual's EI:EE ratio was within, below or above the $95 \%$ confidence limits of agreement between the two measurements (15). The 95\% confidence limits of agreement between $\mathrm{EI}_{2 \times 24-\mathrm{HDR}}$ or $\mathrm{EI}_{7-\mathrm{dFR}}$ and $\mathrm{EE}$ were calculated as:

$95 \% \mathrm{CL}= \pm 2 \sqrt{\left(\mathrm{CV}_{\mathrm{EI}}^{2} / d\right)+\left(\mathrm{CV}_{\mathrm{EE}}^{2} / d\right)}$

Here $d$ is the number of days of assessment, and $\mathrm{CV}_{\mathrm{EI}}$ and $\mathrm{CV}_{\mathrm{EE}}$ are the pooled mean coefficients of variation in EI (by $2 \times 24$-HDRs or $7-\mathrm{dFR}$ ) and EE, respectively. For the $2 \times 24$-HDRs, the number of days was two. To account for the varying number of days (four to seven days) for the food record and the ActiReg ${ }^{\circledR}$ measurements, the mean number of days (6.2 days) was used.

\section{Statistics}

Sample size calculation was based on results from two previous studies, where ActiReg ${ }^{\circledR}$ was used to validate a pre-coded food record in children $(16,17)$. The SD of the mean difference between EE measured with ActiReg $^{\circledR}$ and EI assessed with the food diary was 2 MJ. With a significance level of 0.05 , and a power of $80 \%, 34$ participants of each gender were needed in each age group to be certain of detecting a mean difference between EE and EI of $1 \mathrm{MJ}$.

Data of EI and EE were approximately normally distributed. Differences between EI and EE for groups of children and between the age groups and genders were analysed using paired and unpaired t-tests, respectively. Pearson's correlation coefficients were calculated between EI and EE. Agreement between measurements of EI and EE was visualised using the Bland Altman method of agreement analysis (18). Agreement on category level between EI and EE was examined by classification of EI into quartiles.

The method of triads was used to calculate validity coefficients between the unknown 'true' EI and EI

\footnotetext{
$\overline{{ }^{1} \mathrm{MET}}=$ Metabolic Equivalent, expressing the energy cost of
} physical activities as multiples of BMR estimated by the 7-dFR, EI estimated by the $2 \times 24$ HDRs and EE, respectively (19). If Q, R and M denote the measurements from the $2 \times 24$-HDRs, the 7 -dFR and ActiReg ${ }^{\circledR}$ respectively, and $\mathrm{T}$ denotes the unknown 'true' EI, the validity coefficients can be calculated as follows:

$$
\begin{aligned}
& \mathrm{VC}_{Q T}=\sqrt{r_{Q R} \times r_{Q M} / r_{R M}} \\
& \mathrm{VC}_{R T}=\sqrt{r_{Q R} \times r_{R M} / r_{Q M}} \\
& \text { and } \mathrm{VC}_{M T}=\sqrt{r_{Q M} \times r_{R M} / r_{Q R}}
\end{aligned}
$$

where $r_{Q R}$ is the correlation between the $2 \times 24$-HDRs and the 7-dFR, $r_{Q M}$ the correlation between the $2 \times 24$-HDRs and the ActiReg ${ }^{\circledR}$, and $r_{R M}$ is the correlation between the 7-dFR and ActiReg ${ }^{\circledR}$. This method assumes that the random measurement errors of the three methods are uncorrelated and that there is a positive linear association between each measurement and the true unknown value (19). The 95\% confidence intervals for the validity coefficients were estimated using bootstrap sampling where 10,000 samples of equal size (i.e. the number of participants in the respective age group) were obtained by random sampling with replacement (19). The low number of subjects in each age group precluded the analysis being undertaken separately for each age group.

Differences between the two dietary assessment methods in the proportion of children classified as acceptable reporters, under- or over-reporters, respectively, were tested with the Stuart-Maxwell test. Multiple linear regression analyses were performed for each dietary assessment method with EI:EE as the dependent variable, and age, gender, BMI and parental educational as independent variables.

Statistical differences were considered significant at $P<0.05$. Data were analysed with SPSS version 19.0 for Windows (SPSS Inc., Chicago, IL, USA) and R statistical software 2.9.1 (R Development Core Team, 2009 (http:// www.r-project.org)).

\section{Results}

\section{Study population}

A total of 75 children aged 7-8 years and 70 children aged 12-13 years participated in the study. Data from 14 children were omitted; 12 of these due to invalid ActiReg ${ }^{\circledR}$ measurements, one due to illness during the recording period, and one with less than four completed days of the 7-dFR. Thus, complete records for 67 children aged 7-8 years and 64 children aged $12-13$ years were analysed. Among these, $81 \%$ of the $7-8$ year-old children and $78 \%$ of the $12-13$ year-old children had six or seven days with data both from the 7-dFR and ActiReg ${ }^{\circledR}$. For $94 \%$ of the children, at least one week- 
end day was included with the 7-dFR. At group level, a fairly equal representation of all days of the week was obtained with both dietary assessment methods for both age groups (data not shown). Mean wear time of the ActiReg ${ }^{\circledR}$ was $12.7 \pm 0.6$ hours/day for the 7-8 year-old children and $14.0 \pm 0.7$ hours/day for the $12-13$ year-old children. Characteristics of the participants are presented in Table 1 for each age group.

\section{Differences between $E I$ and $E E$}

In the group of 7-8 year-old children, there was a significant difference between $\mathrm{EI}_{7-\mathrm{dFR}}$ and $\mathrm{EE}(P=0.001)$ but not between $\mathrm{EI}_{2 \times 24-\mathrm{HDR}}$ and $\mathrm{EE}$ (Table 2). In the 12-13 year-old children, both $\mathrm{EI}_{2 \times 24-\mathrm{HDR}}$ and $\mathrm{EI}_{7-\mathrm{dFR}}$ differed significantly from $\mathrm{EE}\left(\mathrm{EI}_{2} \times 24-\mathrm{HDR}: P<0.001\right.$; $\left.\mathrm{EI}_{7-\mathrm{dFR}}: P<0.001\right)$. In the $7-8$ year-olds, $\mathrm{EI}_{2 \times 24-\mathrm{HDR}}$ was $3 \%$ higher and $\mathrm{EI}_{7-\mathrm{dFR}} 7 \%$ lower than $\mathrm{EE}$. In the 12-13 year-olds, $\mathrm{EI}_{2 \times 24-\mathrm{HDR}}$ was $10 \%$ lower and $\mathrm{EI}_{7 \text {-dFR }} 20 \%$ lower than EE. EE and $\mathrm{EI}_{7-\mathrm{dFR}}$ were significantly higher among boys than girls in both the 7-8 year-olds (EE: $P=0.005 ; \mathrm{EI}_{7-\mathrm{dFR}}: P=0.049$ ) and the $12-13$ year-olds (EE: $P<0.001$ EI $_{7-\mathrm{dFR}}: P=0.002$ ). $\mathrm{EI}_{2} \times 24-\mathrm{HDR}$ was also higher among boys in the group of $12-13$ year-old children $(P=0.011)$. However, the absolute differences between estimates of EI and EE, as well as the EI:EE ratios, did not differ between gender within each age group.

\section{Agreement between $\mathrm{El}$ and $\mathrm{EE}$}

The Pearson correlation coefficients between EI and $\mathrm{EE}$ were 0.29 for $\mathrm{EI}_{7-\mathrm{dFR}}$ and 0.51 for $\mathrm{EI}_{2 \times 24-\mathrm{HDR}}$ for both age groups combined. Bland-Altman plots showing the individual differences between values of EI and EE against the mean of EI and EE are presented for each age group and dietary assessment method in Fig. 2. The $95 \%$ limits of agreement were -2.42 and $2.93 \mathrm{MJ} / \mathrm{d}$ for the $2 \times 24$-HDRs and -3.56 and 2.32 for the $7-d F R$ in the 7-8 year-olds, and -5.69 and $3.39 \mathrm{MJ} / \mathrm{d}$ for the $2 \times 24$-HDRs and -7.36 and $2.59 \mathrm{MJ} / \mathrm{d}$ for the $7-\mathrm{dFR}$ in the 12-13 year-olds. For both age groups combined, the $95 \%$ limits of agreement were -4.38 and 3.52 $\mathrm{MJ} / \mathrm{d}$ for the $2 \times 24-\mathrm{HDR}$ and -5.90 and $2.94 \mathrm{MJ} / \mathrm{d}$ for the 7-dFR. The plots illustrate large variation in the degree of misreporting at individual level, and under-reporting as well as over-reporting was observed with both methods. The proportion of individuals correctly classified in the same quartile for both EI and EE are presented in Table 3. Using the method of triads for both age groups combined, the validity coefficient was of $0.81(95 \% \mathrm{CI}: 0.9-0.52)$ for $\mathrm{EI}_{2 \times 24-\mathrm{HDR}}$ and 0.46 (95\% CI: $0.08-0.50)$ for $\mathrm{EI}_{7-\mathrm{dFR}}$.
Proportions of acceptable reporters, under-reporters and over-reporters

The 95\% confidence limits of agreement for the ratios $\mathrm{EI}_{2 \times 24-\mathrm{HDR}}: \mathrm{EE}$ and $\mathrm{EI}_{7-\mathrm{dFR}}: \mathrm{EE}$, defined acceptable reporters by having an EI:EE ratio within the range of $0.75-1.25$ for the $2 \times 24$-HDRs and $0.77-1.23$ for the 7-dFR. The proportions of acceptable reporters, under-reporters and over-reporters with each dietary assessment method are presented in Table 4. No differences between genders were observed. The proportion of children classified as acceptable reporters, underreporters and over-reporters differed significantly between methods (7-8 year-olds: $P=0.005 ; 12-13$ yearolds: $P=0.015)$.

Associations between El:EE and background characteristics In multiple linear regression models with EI:EE as the dependent variable, and age, gender, BMI and parental educational level as independent variables, age remained significantly associated with $\mathrm{EI}_{2 \times 24-\mathrm{HDR}}$ : EE $(P=0.006)$, whereas BMI remained significantly associated with $\mathrm{EI}_{7-\mathrm{dFR}}$ :EE $\quad(P<0.001)$. When entered one-by-one in the multiple linear regression model, BMI and age were significantly associated with EI:EE for both dietary assessment methods $(P<0.001)$.

\section{Discussion}

In the 7-8 year-old children, a modest misreporting was observed with both methods, as EI was 3\% higher than EE with the $2 \times 24$-HDRs and $7 \%$ lower than EE with the 7-dFR. Under-reporting seemed more pronounced in the group of 12-13 year-old children, where EI was $10 \%$ lower than EE with the $2 \times 24$-HDRs and $20 \%$ lower than EE with the 7 -dFR. The tendency towards increasing under-reporting with increasing age from childhood to adolescence is well known, and the assessment of dietary intake in older children and adolescents is recognised as particularly challenging $(2,20)$.

The degree of misreporting of EI in the present study is generally in accordance with findings from several other validation studies of multiple 24-HDRs and precoded food records in children, using doubly labeled water as a reference method (2, 20-23). Moreover, overreporting has been found to be more often associated with 24-HDRs than with food records (3).

In two validation studies among Norwegian 9 yearold and 13 year-old children, EI estimated from precoded food records was also evaluated against EE estimated with ActiReg ${ }^{\circledR}(16,17)$. The authors observed that under-reporting of EI was somewhat higher than in the present study, i.e. $18 \%$ in the 9 year-olds and $24-34 \%$ in the 13 year-olds. Hence, the proportions of children classified as UR with the food record were larger in these Norwegian studies than in the present study. The high 
Table 1. Characteristics of the participants in each age group

\begin{tabular}{|c|c|c|c|c|c|c|c|c|c|c|c|c|}
\hline & \multicolumn{6}{|c|}{ 7-8 years old } & \multicolumn{6}{|c|}{$12-13$ years old } \\
\hline & \multicolumn{2}{|c|}{ Boys $(n=32)$} & \multicolumn{2}{|c|}{ Girls $(n=35)$} & \multicolumn{2}{|c|}{ All $(n=67)$} & \multicolumn{2}{|c|}{ Boys $(n=32)$} & \multicolumn{2}{|c|}{ Girls $(n=32)$} & \multicolumn{2}{|c|}{ All $(n=64)$} \\
\hline & Mean & SD & Mean & SD & Mean & SD & Mean & SD & Mean & SD & Mean & SD \\
\hline Age (years) & 7.5 & 0.5 & 7.6 & 0.6 & 7.5 & 0.5 & 12.6 & 0.6 & 12.7 & 0.7 & 12.5 & 0.5 \\
\hline Height (cm) & $13 \mid$ & 6 & 132 & 5 & $|3|$ & 5 & 161 & 10 & 160 & 7 & 161 & 8 \\
\hline Weight (kg) & 27.4 & 3.2 & 28.8 & 4.8 & 28.1 & 4.2 & 52.2 & 12.8 & 49.5 & 8.6 & 50.9 & 10.9 \\
\hline BMI $\left(\mathrm{kg} / \mathrm{m}^{2}\right)$ & 16.0 & 1.3 & 16.5 & 2.0 & 16.3 & 1.7 & 19.9 & 3.5 & 19.3 & 2.7 & 19.6 & 3.2 \\
\hline \multicolumn{13}{|l|}{ Parental education (\%)* } \\
\hline I: Basic school & \multicolumn{2}{|c|}{21.9} & \multicolumn{2}{|l|}{8.6} & \multicolumn{2}{|c|}{14.9} & \multicolumn{2}{|c|}{15.6} & \multicolumn{2}{|c|}{40.6} & \multicolumn{2}{|c|}{28.1} \\
\hline 2: Vocational education & \multicolumn{2}{|c|}{12.5} & \multicolumn{2}{|l|}{5.7} & \multicolumn{2}{|c|}{9.0} & \multicolumn{2}{|c|}{12.5} & \multicolumn{2}{|c|}{12.5} & \multicolumn{2}{|c|}{12.5} \\
\hline 3: Short higher education & \multicolumn{2}{|c|}{34.4} & \multicolumn{2}{|l|}{54.3} & \multicolumn{2}{|c|}{44.8} & \multicolumn{2}{|c|}{37.5} & \multicolumn{2}{|c|}{34.4} & \multicolumn{2}{|c|}{35.9} \\
\hline 4: Long higher education & \multicolumn{2}{|c|}{31.3} & \multicolumn{2}{|l|}{31.4} & \multicolumn{2}{|c|}{31.3} & \multicolumn{2}{|c|}{34.4} & \multicolumn{2}{|c|}{12.5} & \multicolumn{2}{|c|}{23.4} \\
\hline
\end{tabular}

BMI, body mass index

*Parental educational level. I: Basic school (10 years or less of total education); 2: Vocational education, upper secondary school (I0-12 years); 3: Short higher education (I3-I5 years) (primarily theoretical);

4: Long higher education ( $15+$ years) (primarily theoretical).

Table 2. Energy intake estimated with $2 \times 24-\mathrm{HDRs}\left(\mathrm{EI}_{2 \times 24-\mathrm{HDR}}\right)$ and a seven-day food record $\left(\mathrm{EI}_{7-\mathrm{dFR}}\right)$, energy expenditure estimated with ActiReg ${ }^{\circledR}$ (EE), and the relationship between estimates of EI and EE in each age group

\begin{tabular}{|c|c|c|c|c|c|c|c|c|c|c|c|c|}
\hline & \multicolumn{6}{|c|}{ 7-8 years old } & \multicolumn{6}{|c|}{$12-13$ years old } \\
\hline & \multicolumn{2}{|c|}{ Boys $(n=32)$} & \multicolumn{2}{|c|}{ Girls $(n=35)$} & \multicolumn{2}{|c|}{ All $(n=67)$} & \multicolumn{2}{|c|}{ Boys $(n=32)$} & \multicolumn{2}{|c|}{ Girls $(n=32)$} & \multicolumn{2}{|c|}{ All $(n=64)$} \\
\hline & Mean & SD & Mean & SD & Mean & SD & Mean & SD & Mean & SD & Mean & SD \\
\hline $\mathrm{El}_{2 \times 24-\mathrm{HDR}}(\mathrm{MJ} / \mathrm{d})^{*}$ & $9.2^{\mathrm{a}}$ & 1.6 & $8.7^{\mathrm{a}}$ & 1.4 & 9.0 & 1.5 & $10.6^{\mathrm{a}}$ & 2.6 & $9.1^{\mathrm{b}}$ & 2.0 & 9.9 & 2.4 \\
\hline $\mathrm{El}_{7-\mathrm{dFR}}(\mathrm{MJ} / \mathrm{d}) \dagger$ & $8.5^{\mathrm{a}}$ & 1.7 & $7.7^{\mathrm{b}}$ & 1.2 & 8.1 & 1.5 & $9.4^{\mathrm{a}}$ & 2.1 & $7.9^{\mathrm{b}}$ & 1.6 & 8.6 & 2.0 \\
\hline $\mathrm{EE}(\mathrm{MJ} / \mathrm{d})$ & $9.0^{\mathrm{a}}$ & 0.9 & $8.4^{\mathrm{b}}$ & 0.9 & 8.7 & 0.9 & $12.1^{\mathrm{a}}$ & 2.1 & $10.0^{\mathrm{b}}$ & 1.0 & 11.0 & 2.0 \\
\hline $\mathrm{El}_{2 \times 24-\mathrm{HDR}}-\mathrm{EE}(\mathrm{MJ} / \mathrm{d})$ & $0.2^{\mathrm{a}}$ & 1.3 & $0.3^{\mathrm{a}}$ & 1.4 & 0.3 & 1.3 & $-1.5^{\mathrm{a}}$ & 2.5 & $-0.8^{\mathrm{a}}$ & 2.0 & -1.2 & 2.3 \\
\hline $\mathrm{El}_{7-\mathrm{dFR}}-\mathrm{EE}(\mathrm{MJ} / \mathrm{d})$ & $-0.6^{\mathrm{a}}$ & 1.5 & $-0.7^{\mathrm{a}}$ & 1.4 & -0.6 & 1.5 & $-2.7^{\mathrm{a}}$ & 3.0 & $-2.1^{\mathrm{a}}$ & 1.9 & -2.4 & 2.5 \\
\hline $\mathrm{El}_{2 \times 24-\mathrm{HDR}} / \mathrm{EE}(\mathrm{MJ} / \mathrm{d})$ & $1.02^{\mathrm{a}}$ & 0.14 & $1.04^{\mathrm{a}}$ & 0.16 & 1.03 & 0.15 & $0.89^{\mathrm{a}}$ & 0.21 & $0.92^{\mathrm{a}}$ & 0.19 & 0.90 & 0.20 \\
\hline $\mathrm{El}_{7-\mathrm{dFR}} / \mathrm{EE}(\mathrm{MJ} / \mathrm{d})$ & $0.94^{\mathrm{a}}$ & 0.17 & $0.93^{\mathrm{a}}$ & 0.17 & 0.93 & 0.16 & $0.80^{\mathrm{a}}$ & 0.20 & $0.80^{\mathrm{a}}$ & 0.18 & 0.80 & 0.19 \\
\hline
\end{tabular}

a,b Mean values within a column with unlike superscript letters were significantly different $(P<0.05)$.

* Mean values for $\mathrm{El}_{2 \times 24-\mathrm{HDR}}$ were significantly different from $\mathrm{EE}$ in the group of $12-13$ year-olds $(P<0.00 \mathrm{I})$.

$\dagger$ Mean values for $\mathrm{El}_{7-\mathrm{dFR}}$ were significantly different from $\mathrm{EE}$ in the group of $7-8$ year-olds $(P=0.00 \mathrm{I})$ and $12-13$ year-olds $(P<0.00 \mathrm{I})$. 
(a)

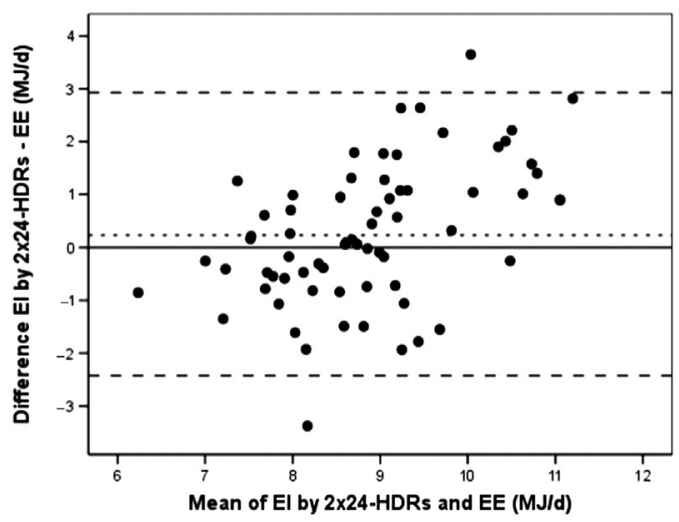

(c)

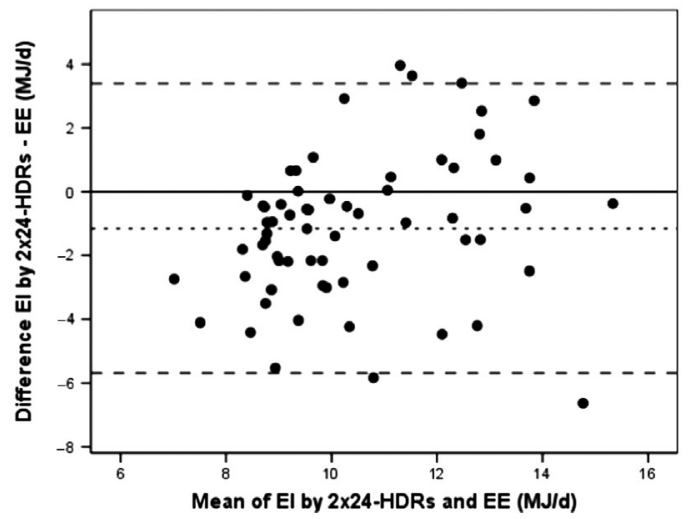

(b)

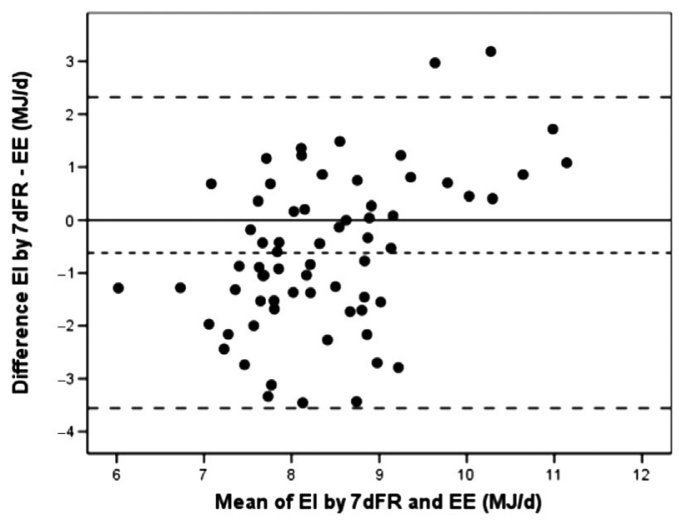

(d)

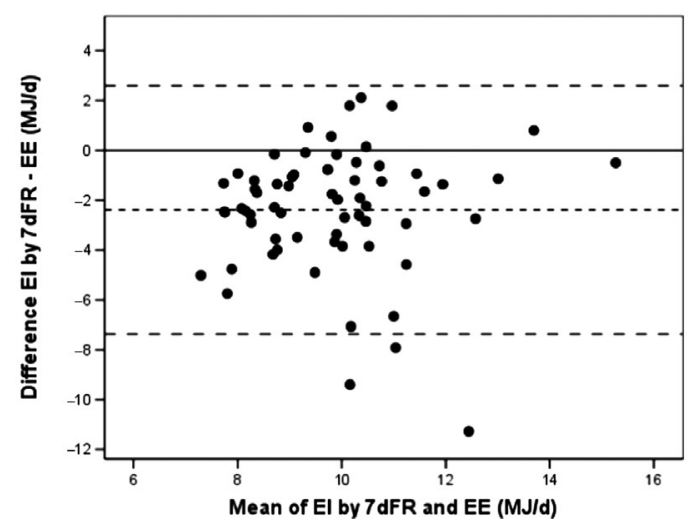

Fig. 2. Bland-Altman plots: the difference between estimated energy intake (EI) and energy expenditure (EE) estimated with ActiReg ${ }^{\circledR}$, plotted against the mean of EI and EE: a and b) 7-8 year-old children ( $\left.n=67\right)$; $\mathrm{c}$ and d) 12-13 year-old children $(n=64)$. ( $(-)$ upper and lower limits of agreement; ( . .) mean difference between EI and EE.

degree of under-reporting in the two Norwegian studies might partly be related to the use of a school class setting, which, in contrast to the present study, may have caused the children to become more physically active because of competition with each other.

Both the $2 \times 24-$ HDRs and the 7-dFR had a high ability to rank subjects in correct and adjacent quartiles

Table 3. Proportions of individuals correctly classified in the same quartile for EI estimated with $2 \times 24-\mathrm{HDRs}\left(\mathrm{EI}_{2 \times 24-\mathrm{HDR}}\right)$ and energy expenditure estimated with $\operatorname{ActiReg}^{\circledR}$ (EE), and for EI estimated with a seven-day food record $\left(\mathrm{EI}_{7-\mathrm{dFR}}\right)$ and $\mathrm{EE}$, respectively, in each age group, $(\%(n))$

\begin{tabular}{lccccc}
\hline & \multicolumn{2}{c}{$\begin{array}{c}7-8 \text { years old } \\
(n=67)\end{array}$} & & \multicolumn{2}{c}{$\begin{array}{c}\text { I2-13 years old } \\
(n=64)\end{array}$} \\
\cline { 2 - 3 } \cline { 6 - 7 } & $\mathrm{El}_{2 \times 24-\mathrm{HDR}}$ & $\mathrm{El}_{7-\mathrm{dFR}}$ & & $\mathrm{El}_{2 \times 24-\mathrm{HDR}}$ & $\mathrm{El}_{7-\mathrm{dFR}}$ \\
\hline Same quartile & $46(3 \mathrm{I})$ & $30(20)$ & $36(23)$ & $34(22)$ \\
Same or adjacent quartile & $76(5 \mathrm{I})$ & $73(49)$ & $83(53)$ & $70(45)$ \\
Gross miss classification & $3(2)$ & $7(5)$ & & $3(2)$ & II (7) \\
\hline
\end{tabular}

in both age groups. Moreover, the $2 \times 24$-HDRs appeared to perform slightly better in ranking of individuals. As illustrated in the Bland-Altman plots, large variation at the individual level occurred in both age groups. However, accuracy at the individual level is generally poor in validation studies of EI (2). Furthermore, since the use of objective measurements of $\mathrm{EE}$ as a reference for evaluation of EI measurements is based on the assumption of energy balance, exact agreement between EI and EE at the individual level is unlikely during a short recording period due to normal day-to-day variation in both EI and EE (14).

In studies like the present one, where data from a dietary assessment method, a reference method and a biomarker, or another objective method is available, the method of triads can be used. This method is a triangular approach that uses the correlations between each of the three methods to estimate a validity coefficient (VC). This coefficient expresses the correlation between reported intake and the unknown 'true' intake (19). In accordance with the other analyses from the present study, the higher validity coefficients of $\mathrm{EI}_{2} \times 24-\mathrm{HDR}$ 
Table 4. Proportions of acceptable reporters, under-reporters and over-reporters defined for the $2 \times 24$-HDRs and the seven-day food record $(7-d F R)$ in each age group*, $(\%(n))$

\begin{tabular}{lcccccc}
\hline & \multicolumn{2}{c}{$\begin{array}{c}7-8 \text { years old } \\
(n=67) \dagger\end{array}$} & & \multicolumn{2}{c}{$\begin{array}{c}\text { I2-13 years old } \\
(n=64) \dagger\end{array}$} \\
\cline { 2 - 3 } \cline { 5 - 6 } & $2 \times 24-H D R s$ & $7-d F R$ & & $2 \times 24-H D R s$ & $7-d F R$ \\
\hline Acceptable reporters & $93(62)$ & $81(54)$ & & $70(45)$ & $58(37)$ \\
Under-reporters & $2(1)$ & $16(11)$ & & $23(15)$ & $42(27)$ \\
Over-reporters & $6(4)$ & $3(2)$ & & $6(4)$ & $0(0)$ \\
\hline
\end{tabular}

*Participants were classified as acceptable reporters, under-reporters, or over-reporters according to whether the individual's El:EE ratio was within, below or above the $95 \%$ confidence limits of agreement between the two measurements.

$\dagger$ Proportions were significantly different between methods $(P=0.005)$. \$Proportions were significantly different between methods $(P=0.015)$.

(VC: 0.81) than of $E I_{7-d F R}$ (VC: 0.46) indicated that EI was closer to the unknown 'true' value when estimated with the $2 \times 24$-HDRs than with the $7-d F R$. The method of triads assumes that the random measurement errors of the three methods are uncorrelated, however, it must be recognised, that some degree of correlation cannot be ruled out between the two dietary assessment methods.

A possible reason for why reported EI was higher with the $2 \times 24$-HDRs than with the 7 -dFR, is that the design with a comprehensive interview incorporates a great effort in collecting every detail of the dietary intake. This includes a thorough question technique using systematic probing questions and a personal contact with the interviewer during the recalls, which may help both children and their parents in reporting all relevant information and in keeping their motivation high.

Although these aspects of the recalls may have several advantages, social desirability is a prominent source of bias in dietary assessment that may be enhanced by the personal contact with an interviewer and thus have more influence on the reporting with the $2 \times 24$-HDRs than with the 7-dFR $(25,26)$. Both children's self-reported dietary intake as well as their actual intake may be biased by the awareness of the reporting. Moreover, parents may wish to appear as having good parenting skills and let this influence the children's food intake on reporting days. With both methods, participants knew in advance which days the dietary intake was going to be reported. As it may be easier to keep a more socially desirable diet on two non-consecutive days than during seven consecutive days, modification of the children's dietary intake might have been more likely with the $2 \times 24$-HDRs. This notion was supported by analyses of the nutrient and food intake, which showed a tendency for the participants to report a healthier diet with the $2 \times 24$-HDRs than with the 7-dFR, as discussed by Trolle et al. (8).

Similar to findings from other studies $(23,27)$, a tendency towards increasing underreporting with increasing BMI was observed. Understanding why and how misreporting occurs is complicated, and the psychosocial and behavioural aspects related to misreporting is difficult to assess (25).

The reference method and the test method should preferably cover the same time period, however, this was only possible with the 7-dFR and not the $2 \times 24$-HDRs. Due to the logistic difficulties of getting the ActiReg ${ }^{\circledR}$ to the participants before each recall, as well as the high participation burden, the EE measurements were obtained only on the same days as the food record was filled in. Recording over a week is often used to reflect the habitual behaviour in studies of dietary intake and physical activity (9).

EE measurements in the present study was obtained by use of ActiReg ${ }^{\circledR}$, as this was a validated method (10), which has been used to measure total $\mathrm{EE}$ in other validation studies in children $(16,17)$. The ActiReg ${ }^{\circledR}$ system uses the combined recording of body position and movement to assess energy expenditure, and has demonstrated a close relationship at group level with DLW in young adults (10). However, like other objective instruments used to measure $\mathrm{EE}$ in free-living subjects, ActiReg $^{\circledR}$ shows considerable variation at the individual level, and the use of ActiReg ${ }^{\circledR}$ has some limitations, including the ability to detect high intensity physical activity, arm work, carrying loads and water activities, while certain moderate intense physical activities such as walking and running slowly may tend to be overestimated $(10,28)$. These issues might introduce a larger source of measurement error in children than in adults since the algorithms used, were initially developed for adults.

Strengths of the present study include that EE was measured with an objective method that is likely to have a minimum of correlated errors with the two dietary assessment methods. Moreover, the design allowed two dietary assessment methods to be compared with objective measurements of $\mathrm{EE}$, which also enabled us to use the method of triads. The method of triads has been used in other studies for validation of nutrient intake and for validation of biomarkers for intake of different nutrients $(29,30)$, but to our knowledge, use of the method of triads to compare EI from two different dietary recording methods with objective measurements of EE has not been presented before.

Given the heavy workload of the study, it must be recognised that the sample of participants are volunteers, higher educated than the general Danish population and most probably more motivated and health conscious than usual. 


\section{Conclusion}

At group level, misreporting of EI seemed modest with both the $2 \times 24$-HDRs and the $7-\mathrm{dFR}$ in the 7-8 yearolds when compared to EE measured with ActiReg ${ }^{\circledR}$. Under-reporting appeared to be more evident in the 12 13 year-olds, especially with the 7-dFR. Compared to measurements of EE, the $2 \times 24$-HDRs seemed to perform slightly better than the 7-dFR in terms of ranking of individuals according to EI.

\section{Acknowledgements}

The authors are grateful to the interviewers Anne Arendt, Mia Hjort Frandsen and Inger Merete Licht Hansen, the data management team, Karsten Kørup, Henrik Hartkopp, Karin Hess Ygil and Tue Christensen, and to Majken Ege for taking care of coordinating activities. Furthermore, the authors express their appreciation to all the participating children, parents and other proxy persons. The authors acknowledge community funding under the Sixth Framework Program for the EFCOVAL project (FOOD-CT-2006-022895). The content of this article reflects only the author's views and the Community is not liable for use that may be made of the information contained therein. B.W.R. participated in the data collection, analysed the data and wrote the manuscript. E.T. and L.F.A., as part of the EFCOVAL consortium, were responsible for the study design. J.M., M.V.G., P.B.B., L.F.A. and E.T. participated in critical revision of the manuscript and the statistical analyses.

\section{Conflict of interest and funding}

None of the authors had a financial or personal conflict of interest. There was community funding under the Sixth Framework Program for the EFCOVAL project (FOOD-CT-2006-022895).

\section{References}

1. Elmadfa I, Meyer A, Nowak V, Hasenegger V, Putz P, Verstraeten R, et al. European nutrition and health report 2009. Ann Nutr Metab 2009; 55 Suppl 2: S1-S40.

2. Livingstone MB, Robson PJ, Wallace JMW. Issues in dietary intake assessment of children and adolescents. Br J Nutr 2004; 92 Suppl 2: S213-S22.

3. Burrows TL, Martin RJ, Collins CE. A systematic review of the validity of dietary assessment methods in children when compared with the method of doubly labeled water. J Am Diet Assoc 2010; 110: 1501-10.

4. Ainslie P, Reilly T, Westerterp K. Estimating human energy expenditure: a review of techniques with particular reference to doubly labelled water. Sports Med 2003; 33: 683-98.

5. de Boer EJ, Slimani N, van't Veer P, Boeing H, Feinberg M, Leclercq $\mathrm{C}$, et al. The European food consumption validation project: conclusions and recommendations. Eur J Clin Nutr 2011; 65 Suppl 1: S102-7.

6. Andersen LF, Lioret S, Brants H, Kaic-Rak A, de Boer EJ, Amiano P, et al. Recommendations for a trans-European dietary assessment method in children between 4 and 14 years. Eur J Clin Nutr 2011; 65 Suppl 1: S58-64.

7. Slimani N, Casagrande C, Nicolas G, Freisling H, Huybrechts I, Ocké MC, et al. The standardized computerized 24-h dietary recall method EPIC-Soft adapted for pan-European dietary monitoring. Eur J Clin Nutr 2011; 65 Suppl 1: S5-15.
8. Trolle E, Amiano P, Ege M, Bower E, Lioret S, Brants H, et al. Evaluation of $2 \times 24$-h dietary recalls combined with a foodrecording booklet, against a 7-day food-record method among schoolchildren. Eur J Clin Nutr 2011; 65 Suppl 1: S77-83.

9. Biltoft-Jensen A, Matthiessen J, Rasmussen LB, Fagt S, Groth MV, Hels O. Validation of the Danish 7-day pre-coded food diary among adults: energy intake v. energy expenditure and recording length. Br J Nutr 2009; 102: 1838-46.

10. Hustvedt BE, Christophersen A, Johnsen LR, Tomten H, McNeill G, Haggarty P, et al. Description and validation of the ActiReg: a novel instrument to measure physical activity and energy expenditure. Br J Nutr 2004; 92: 1001-8.

11. FAO/WHO/UNU (1985). Energy and protein requirements. WHO Technical Report Series, No. 724. Geneva: WHO.

12. Matthiessen J, Biltoft-Jensen A, Rasmussen LB, Hels O, Fagt S, Groth MV. Comparison of the Danish physical activity questionnaire with a validated position and motion instrument. Eur J Epidemiol 2008; 23: 311-22.

13. Tudor-Locke C, Johnson WD, Katzmarzyk PT. US population profile of time-stamped accelerometer outputs: impact of wear time. Phys Act Health 2011; 8: 693-8.

14. Black AE. The sensitivity and specificity of the Goldberg cut-off for EI:BMR for identifying diet reports of poor validity. Eur J Clin Nutr 2000; 54: 395-404.

15. Livingstone MB, Robson PJ, Black AE, Coward WA, Wallace JM, McKinley MC, et al. An evaluation of the sensitivity and specificity of energy expenditure measured by heart rate and the Goldberg cut-off for energy intake: basal metabolic rate for identifying mis-reporting of energy intake by adults and children: a retrospective analysis. E J Clin Nutr 2003; 57: 45563 .

16. Andersen LF, Pollestad ML, Jacobs DR Jr, Løvø A, Hustvedt BE. Validation of a pre-coded food diary used among 13-year-olds: comparison of energy intake with energy expenditure. Public Health Nutr 2005; 8: 1315-21.

17. Lillegaard IT, Andersen LF. Validation of a pre-coded food diary with energy expenditure, comparison of under-reporters v. acceptable reporters. Br J Nutr 2005; 94: 998-1003.

18. Bland JM, Altman DG. Statistical methods for assessing agreement between two methods of clinical measurement. Lancet 1986; 1: 307-10.

19. Ocké MC, Kaaks RJ. Biochemical markers as additional measurements in dietary validity studies: application of the method of triads with examples from the European Prospective Investigation into Cancer and Nutrition. Am J Clin Nutr 1997; 65 Suppl 4: S1240-S5.

20. Bandini LG, Must A, Cyr H, Anderson SE, Spadano JL, Dietz WH. Longitudinal changes in the accuracy of reported energy intake in girls 10-15 y of age. Am J Clin Nutr 2003; 78: $480-4$.

21. Bandini LG, Cyr H, Must A, Dietz WH. Validity of reported energy intake in preadolescent girls. Am J Clin Nutr 1997; 65 Suppl: S1138-41.

22. Champagne CM, Baker NB, DeLany JP, Harsha DW, Bray GA. Assessment of energy intake underreporting by doubly labeled water and observations on reported nutrient intakes in children. J Am Diet Assoc 1998; 98: 426-33.

23. Singh R, Martin BR, Hickey Y, Teegarden D, Campbell WW, Craig BA, et al. Comparison of self-reported, measured, metabolizable energy intake with total energy expenditure in overweight teens. Am J Clin Nutr 2009; 89: 1744-50.

24. Lillegaard IT, Loken EB, Andersen LF. Relative validation of a pre-coded food diary among children, under-reporting varies with reporting day and time of the day. Eur J Clin Nutr 2007; 61: 61-8. 
25. Maurer J, Taren DL, Teixeira PJ, Thomson CA, Lohman TG, Going SB, et al. The psychosocial and behavioral characteristics related to energy misreporting. Nutr Rev 2006; 64: 53-66.

26. Klesges LM, Baranowski T, Beech B, Cullen K, Murray DM, Rochon J, et al. Social desirability bias in self-reported dietary, physical activity and weight concerns measures in 8- to 10-year-old African-American girls: results from the Girls Health Enrichment Multisite Studies (GEMS). Prev Med 2004; 38 Suppl: S78-87.

27. Lioret S, Touvier M, Balin M, Huybrechts I, Dubuisson C, Dufour A, et al. Characteristics of energy under-reporting in children and adolescents. Br J Nutr 2011; 105: 1671-80.

28. Arvidsson D, Slinde F, Hulthén L. Free-living energy expenditure in children using multi-sensor activity monitors. Clin Nutr 2009; 28: 305-12.

29. Andersen LF, Veierød MB, Johansson L, Sakhi A, Solvoll K, Drevon CA. Evaluation of three dietary assessment methods and serum biomarkers as measures of fruit and vegetable intake, using the method of triads. Br J Nutr 2005; 93: 519-27.

30. Verkleij-Hagoort AC, de Vries JH, Stegers MP, Lindemans J, Ursem NT, Steegers-Theunissen RP. Validation of the assessment of folate and vitamin B12 intake in women of reproductive age: the method of triads. Eur J Clin Nutr 2007; 61: 610-5.

*Berit W. Rothause

Division of Nutrition, National Food Institute

Technical University of Denmark

Mørkhøj Bygade 19

DK-2860 Søborg

Denmark

Tel: +453588 7I58

Fax: +4535887119

Email: bewro@food.dtu.dk 